\title{
Insecticidal Effect and Residual Action of Fenitrothion and Esfenvalerate on Sitophilus oryzae and S. zeamais (Coleoptera: Curculionidae) in Stored Maize and Wheat
}

\author{
J. A. Vásquez-Castro, ${ }^{1}$ G. C. de Baptista, ${ }^{2}$ C. D. Gadanha Jr., ${ }^{3}$ and L. R. P. Trevizan ${ }^{2}$ \\ ${ }^{1}$ Departamento de Entomología, Universidad Nacional Agraria La Molina, Avenida La Molina, s/n Apartado 456, Lima 100, Peru \\ ${ }^{2}$ Departamento de Entomologia e Acarologia, Escola Superior de Agricultura "Luiz de Queiroz," USP, 13418-900 Piracicaba, SP, Brazil \\ ${ }^{3}$ Departamento de Engenharia de Biossistemas, Escola Superior de Agricultura "Luiz de Queiroz," USP, \\ 13418-900 Piracicaba, SP, Brazil
}

Correspondence should be addressed to J. A. Vásquez-Castro, jaque@lamolina.edu.pe

Received 27 April 2012; Accepted 25 July 2012

Academic Editors: A. D. Arencibia, M. R. Mosquera-Losada, M. Sisterna, and Z. Yanqun

Copyright ( $\odot 2012$ J. A. Vásquez-Castro et al. This is an open access article distributed under the Creative Commons Attribution License, which permits unrestricted use, distribution, and reproduction in any medium, provided the original work is properly cited.

\begin{abstract}
Among the pests that attack stored maize and wheat grain, Sitophilus oryzae (L.) and S. zeamais Motsch (Coleoptera: Curculionidae) are the most destructive. This paper is aimed at the study of the insecticidal effect and the residual action of organophosphate fenitrothion, pyrethroid esfenvalerate, and the mixture of both on S. oryzae and S. zeamais in stored maize and wheat. Grains were treated in order to obtain theoretical concentrations of 10 and/or $0.5 \mathrm{mg} \cdot \mathrm{kg}^{-1}$ fenitrothion and esfenvalerate, respectively. The effectiveness experiments were installed as of 15, and 30 days, and subsequently at monthly intervals as of 12 months after grain treatment, or until mortality ceased in the plots. After mortality evaluation happened all individuals were eliminated, either dead or alive, and grains were kept for 60 days to assess the number of emerged progeny. The comparison of mortality curves of the pest species within each combination of grain type and insecticide showed significant differences. In general, the mortality of $S$. oryzae decreased faster than that of $S$. zeamais considering the grain type-insecticide combination. Esfenvalerate was ineffective in all combinations. Higher mortality of both species was observed on wheat grains treated with fenitrothion and fenitrothion + esfenvalerate mixture. Best results as to progeny control were obtained with fenitrothion and fenitrothion + esfenvalerate mixture. The factors that influenced the pest control are discussed in the present work.
\end{abstract}

\section{Introduction}

Stored products are attacked by pests which cause quantitative and qualitative losses reaching $10 \%$ grain production as per FAO and the Brazilian Ministry of Agriculture, Agribusiness and Supply, reaching a 10\% of grain production in Brazil [1].

Due to the high biotic potential and cross-infestation, $S$. oryzae and S. zeamais are considered the most destructive pests attacking stored grains of maize and wheat in Brazil [2]. Although the two species can develop in both types of grains, S. oryzae presents marked preference for wheat and $S$. zeamais for maize [3].

Nonetheless, several studies have demonstrated the high efficiency of organophosphates to control Sitophilus spp. [4-6], and the resistance of Brazilian populations of $S$. oryzae to this class of insecticides have also been stated [7]. Opposite situation is observed in S. zeamais, as only slight resistance to chorpyriphos methyl has been recently reported [8]. The increase in costs of development and registration of new pesticides has caused the decrease in the number of these substances (organophosphates, carbamates, 
and pyrethroids) available for the treatment of stored grains. Consequently, the problem of resistance has been aggravated [9]. On the other hand, the influence of the grain type on insecticide effectiveness has also been stated [10-12].

In toxicological studies the assessment of pest population growth provides more precise information regarding the impact of insecticides on targeted and nontargeted organisms than those estimates of lethal dose/concentration fifty $\left(\mathrm{LD}_{50}, \mathrm{LC}_{50}\right)$ [13]. In this regard, several studies have shown the importance of evaluating the production of progeny in grain protection experiments with residual insecticides [1416].

In Brazil, protective insecticides currently registered for the treatment of stored grains of maize and/or wheat are the organophosphates fenitrothion, malathion, and pirimiphosmethyl and the pyrethroids bifenthrin, deltamethrin, esfenvalerate, and permethrin [17]. These insecticides present security intervals (SI) between 15 and 60 days, except fenitrothion with SI of 120 and 180 days for wheat and maize, respectively. The long security interval of fenitrothion makes it an insecticide slightly used in storing units; under these conditions this substance tends to fall into disuse, thus, leading to the loss of one more of the few insecticides registered for the treatment of stored grains, making it difficult for the management of pest resistance to insecticides. Esfenvalerate is a relatively new insecticide with physicochemical properties similar to fenvalerate, but it presents high efficiency to control insects because it holds more than $80 \%$ of isomers with insecticidal activity in contrast to $22 \%$ of fenvalerate [18].

As stated, several factors must be taken into account in pest control of stored products. Therefore, targets of this study were to evaluate the insecticidal and residual effect of fenitrothion and esfenvalerate used alone and combined against S. oryzae and S. zeamais, and to assess the influence of the type of grain (maize and wheat) on insecticide efficiency and on progeny control (F1).

\section{Material and Methods}

2.1. Insects. S. oryzae and S. zeamais were obtained from the insect rearing laboratories of the Center of Nuclear Power and Agriculture of Universidade de São Paulo_-CENA/USP, Piracicaba, SP and Centro Nacional de Pesquisa de Milho e Sorgo (the National Research Center of Corn and Sorgo)CNPMS/EMBRAPA, Sete Lagoas, MG, respectively. Both populations were reared in these laboratories for over 20 years with an absence of selective pressure by insecticides, thus, considered as reference susceptible lines. Both species were transferred to the sector of insecticide toxicology of the Department of Entomology and Acarology of Escola Superior de Agricultura "Luiz de Queiroz," ESALQ/USP, in Piracicaba, SP, and reared insecticide-free on grains of maize and wheat until the installation of the experiments.

2.2. Insecticides. Business products used were Sumigranplus $(500 \mathrm{~g}$ fenitrothion $+25 \mathrm{~g}$ esfenvalerate per liter of the commercial product), Sumigran (500 g fenitrothion per liter of the commercial product), and Sumidan ( $25 \mathrm{~g}$ esfenvalerate per liter of the commercial product), produced by Iharabras Chemical S.A., Sorocaba, SP, Brazil.

2.3. Grain Treatment and Bioassays. Grains of maize and wheat were treated in order to obtain the theoretical concentration of 10 and $0.5 \mathrm{mg} \cdot \mathrm{kg}^{-1}$ fenitrothion and/or esfenvalerate, respectively. The method of application used was proposed by Vásquez-Castro et al. [19, 20]. Three replications were performed for each type of grain and each insecticide. Temperature and relative humidity while spraying ranged $16-18^{\circ} \mathrm{C}$ and $72-79 \%$, respectively. After spraying, grains were placed in plastic bags kept open and stored in the laboratory without temperature or humidity control.

For the effectiveness tests, $40 \mathrm{~g}$ of grains were placed into plastic pots and infected with 40 unsexed adult insects aged 10 to 20 days. After this, the pots were closed with voile fabric and elastic and kept in the laboratory without temperature or humidity control. Mortality evaluation was performed 15 days after infestation, considering the immobile individuals dead, that is, unable to move even when stimulated by an incandescent light source placed a few centimeters away from them. After evaluation, all the insects were eliminated, either dead or alive, and grains were stored for 60 days to assess the number of emerged progeny (F1) during this period. The effectiveness experiments were installed as of 15, and 30 days and subsequently at monthly intervals up to 12 months after grain treatment, or until mortality ceased, totaling 387 plots.

2.4. Statistical Analysis. As the variable response (number of dead insects, $d=40$ insects) of the experiment has a binomial distribution, in the effectiveness tests, data were analyzed using the logistic regression, through the logistic procedure of SAS [21]. First, 72 models were adjusted, from the simplest model whose linear predictor contained only the intercept $(\eta=\alpha)$, to the more complicated model whose linear predictor contained intercepts and slope coefficients (related to time after insecticide application) different for the combinations of insecticide levels, pest species, and type of grain $\left(\eta=\alpha_{i j k}+\beta_{i j k} x\right)$. To verify the adjustment of these models, the statistics deviance and the generalized Person $X^{2}$ Information Criterion, (AIC) as an auxiliary in selecting the most appropriate model $[21,22]$. Based on the model selected in the previous step, estimates were calculated for $\alpha_{s}, \beta_{s}$ and lethal time 50 , when mortality as of $50 \%$ insects occurs.

For the analysis of progeny (F1) data, at first it was considered that this variable comprises a Poisson distribution since it is a count, but due to the overdispersion of the data, the response variable was evaluated using the negative binomial distribution, through the GENMOD procedure of SAS [21]. Pest species, insecticide, type of grain (categorical variables), and time after the insecticide application (quantitative variable) were taken as explanatory variables.

\section{Results and Discussion}

3.1. Effectiveness Experiments. After evaluating the 72 models, model $\left(\eta=\alpha_{i j k}+\beta_{i j k} x\right)$ was chosen. This model showed 
TABLE 1: Residual degrees of freedom, deviances and $X^{2}$ for the linear logistic model, estimates of $\alpha$ and $\beta$ parameters, probability descriptive level for the effect of linear regression and lethal time $50\left(\mathrm{LT}_{50}\right)$.

\begin{tabular}{|c|c|c|c|c|c|c|c|c|c|}
\hline \multirow{2}{*}{ Type of grain } & \multirow{2}{*}{ DF. } & \multicolumn{2}{|c|}{ Deviance } & \multicolumn{2}{|c|}{$X^{2}$} & \multicolumn{2}{|c|}{ Parameters } & \multirow{2}{*}{ Linear regression $\left(\operatorname{Pr}>\chi^{2}\right)$} & \multirow{2}{*}{$\mathrm{LT}_{50}$ (months) } \\
\hline & & Value & $\operatorname{Pr}>\chi^{2}$ & Value & $\operatorname{Pr}>\chi^{2}$ & $\alpha$ & $\beta$ & & \\
\hline \multicolumn{10}{|c|}{ Esfenvalerate $\times$ S. oryzae } \\
\hline Maize & 36 & 13.37 & 0.9998 & 16.37 & 0.9980 & -3.351 & -1.216 & 0.0056 & - \\
\hline Wheat & 36 & 13.37 & 0.9998 & 16.37 & 0.9980 & -4.749 & -1.216 & 0.0056 & - \\
\hline \multicolumn{10}{|c|}{ Esfenvalerate $\times S$. zeamais } \\
\hline Maize & 39 & 34.73 & 0.6651 & 30.02 & 0.8486 & -1.153 & -0.359 & $<0.0001$ & - \\
\hline Wheat & 39 & 34.73 & 0.6651 & 30.02 & 0.8486 & -1.313 & -0.359 & $<0.0001$ & - \\
\hline \multicolumn{10}{|c|}{ Fenitrothion $\times S$. oryzae } \\
\hline Maize & 72 & 61.20 & 0.8141 & 53.19 & 0.9528 & 4.101 & -0.668 & $<0.0001$ & 6.14 \\
\hline Wheat & 72 & 61.20 & 0.8141 & 53.19 & 0.9528 & 7.581 & -0.668 & $<0.0001$ & 11.35 \\
\hline \multicolumn{10}{|c|}{ Fenitrothion $\times S$. zeamais } \\
\hline Maize & 75 & 13.83 & 1.0000 & 10.88 & 1.0000 & 27.382 & -2.361 & $<0.0001$ & 11.60 \\
\hline Wheat & 75 & 13.83 & 1.0000 & 10.88 & 1.0000 & 32.511 & -2.361 & $<0.0001$ & $\geq 13.77$ \\
\hline \multicolumn{10}{|c|}{ Fenitrothion + Esfenvalerate $\times$ S. oryzae } \\
\hline Maize & 72 & 62.51 & 0.7802 & 51.08 & 0.9707 & 3.897 & -0.632 & $<0.0001$ & 6.17 \\
\hline Wheat & 72 & 62.51 & 0.7802 & 51.08 & 0.9707 & 7.665 & -0.632 & $<0.0001$ & 12.14 \\
\hline \multicolumn{10}{|c|}{ Fenitrothion + Esfenvalerate $\times$ S. zeamais } \\
\hline Maize & 75 & 5.93 & 1.0000 & 4.03 & 1.0000 & 31.083 & -2.650 & $<0.0001$ & 11.73 \\
\hline Wheat & 75 & 5.93 & 1.0000 & 4.03 & 1.0000 & 35.950 & -2.650 & $<0.0001$ & $\geq 13.57$ \\
\hline
\end{tabular}

significant differences between $\alpha_{s}$ of insecticides, pest species, and type of grain, while $\beta_{s}$ only varied as to the first two factors.

Table 1 shows the estimated values of $\alpha$ and $\beta$ for each combination of insecticide, pest species, and type of grain, as well as the time of occurrence of 50\% mortality based on the estimates of these two parameters. Considering the residual deviances and $X^{2}$ for each combination of insecticide-pest species and the parallel lines logistic model between the two types of grain, all models fitted well to the data, and the lowest significance level was 0.6651 for esfenvalerate used to control S. zeamais. Moreover, a significant effect $(P>0.05)$ of linear regression was observed in all cases, that is, the effect of time after insecticide application on insect mortality occurred. In some cases it was not possible to estimate $\mathrm{LT}_{50}$, because mortality values below $50 \%$ were observed at the beginning of the experiments, as observed for both Sitophilus species exposed to esfenvalerate, in maize and wheat. On the other hand, the mortality of $S$. zeamais on wheat grains treated with fenitrothion and the fenitrothion + esfenvalerate mixture was $98 \%$ at the end of the trials; hence, the value estimated for $\mathrm{LT}_{50}$ (13.77 and 13.57 months, resp.) is only a reference because it can be any other value higher than the estimated.

In all cases, the estimated $\mathrm{LT}_{50}$ was lower in maize grains than in wheat grains indicating that the period of protection provided by insecticides depends not only on the chemical molecule and pest species but also on the type of grain.

Figures 1-3 show the mortalities observed and adjusted curves, respectively, for each insecticide and each combination of pest species and type of grain. No insect mortality occurred in the 387 evaluations of control treatments.
In general, esfenvalerate presented low effectiveness in controlling $S$. oryzae and S. zeamais (Figure 1(a)), reaching maximum mortality of $21 \%$ for both species since the first assessment as of 15 days, this fact made it impossible to estimate the corresponding value $\mathrm{LT}_{50}$.

Mortality curves of both types of grain can be considered similar for esfenvalerate, so in $S$. oryzae $(P=0.1193)$ as in $S$. zeamais $(P=0.3365)$. While fenitrothion, and fenitrothion + esfenvalerate $\alpha_{s}$ the two types of grain presented significant differences $(P<0.0001)$ in the two pest species, indicating that mortality curves are significantly different for both types of grain in the two species and in the two insecticide treatments (Figures $1(\mathrm{~b})$ and $1(\mathrm{c})$ ). The $\mathrm{LT}_{50}$ values were lower in maize than in wheat for these insecticides, and for $S$. zeamais the mortalities in the two types of grain were similar until the tenth month of evaluation.

Comparison by difference of mortality curves deviances of pest species within each combination of type of grain and insecticide showed significant differences $(P<0.0001)$. In general, $S$. oryzae mortality decreased faster than $S$. zeamais mortality in the combinations of insecticide and type of grain, causing lower $\mathrm{LT}_{50}$ for this pest species.

The insecticide esfenvalerate caused the lower mortalities in all insecticide-grain type combinations, and in all cases the mortality curve of this insecticide was significantly different $(P<0.0001)$ from that of the other insecticides (Figures 2 and 3). The mortality curves of the insecticides fenitrothion, and fenitrothion + esfenvalerate were very similar for all combinations of pest species and type of grain (Figures 2 and 3 ), and significant difference occurred only between the two curves of wheat and for the S. oryzae species (Figure 3(a)), whose mortality for insecticide fenitrothion was slightly 


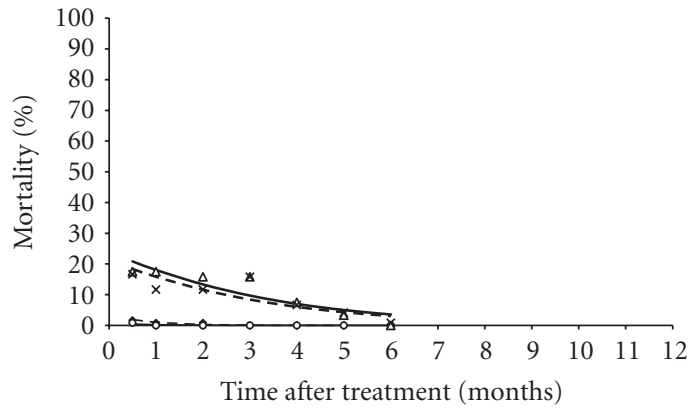

- S. oryzae-corn

- S. oryzae-wheat

$\triangle$ S. zeamais-corn

$\times$ S. zeamais-wheat
- - S. oryzae-corn est.

- S. oryzae-wheat est.

- S. zeamais-corn est.

- - S. zeamais-wheat est.

(a)

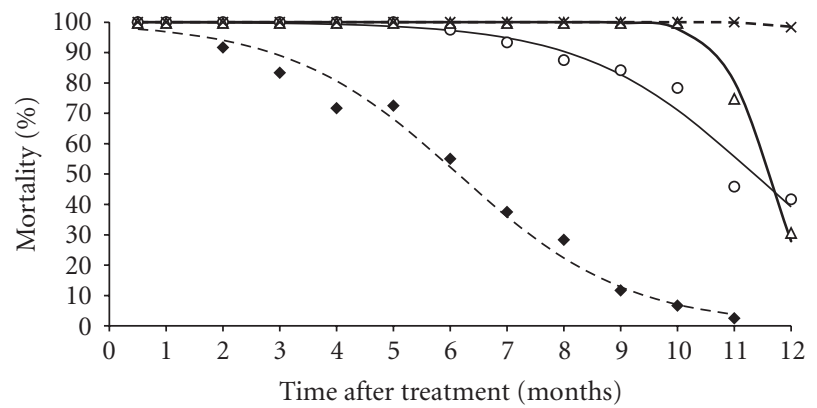

- S. oryzae-corn

- S. oryzae-wheat

$\Delta$ S. zeamais-corn

$\times S$. zeamais-wheat
- - S. oryzae-corn est.

- S. oryzae-wheat est.

- S. zeamais-corn est.

- - S. zeamais-wheat est. (b)

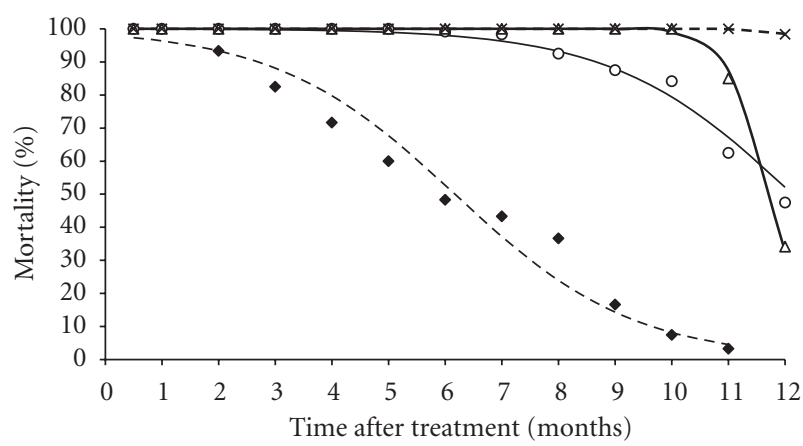

- S. oryzae-corn

- S. oryzae-wheat

$\Delta$ S. zeamais-corn

$\times S$. zeamais-wheat
- - S. oryzae-corn est.

S. oryzae-wheat est.

- S. zeamais-corn est.

-- - S. zeamais-wheat est.

(c)

FiguRE 1: Mortality percentage-figures observed and adjusted curves (stat.) using the linear logistic model as to time after treatment, comparing pest species and types of grain, resulting from the application of esfenvalerate (a), fenitrothion (b), and fenitrothion + esfenvalerate mixture (c).

lower than that caused by the fenitrothion + esfenvalerate mixture as of the seventh month of evaluation, that is, affecting the $\mathrm{LT}_{50}$ parameter.

Although esfenvalerate has never been used against those studied populations, it proved to be ineffective in controlling both species; probably due to a DDT cross-resistance phenomenon, an insecticide widely used in the past to control pests in warehouses holding similar action mechanism of pyrethroids. This phenomenon was observed in S. granarius (L.) by Prickett [23], in S. oryzae by Heather [24], and in $S$. zeamais by Guedes [25]. On the other hand, it is also known of pyrethroids increasing-efficiency by adding the synergist piperonyl butoxide $[8,26,27]$. So, fenvalerate was efficient in controlling $S$. zeamais when synergized with piperonyl butoxide [28] and the mixture fenitrothion + fenvalerate + piperonyl butoxide became efficient to control several lines of S. oryzae in stored wheat [29]. Thus, considering that esfenvalerate has greater insecticidal activity than its predecessor fenvalerate [18], hence, the use of the synergist piperonyl butoxide could improve this insecticide's efficiency in stored grains protection.

In general, a higher tolerance of $S$. oryzae to fenitrothion, and fenitrothion + esfenvalerate mixture was observed compared to $S$. zeamais. An explanation to these results is that $S$. zeamais has a great ability to migrate from warehouse to field and vice-versa $[30,31]$. This behavior would cause a great gene flow amid populations of this species, thus, favoring the dilution of resistance. On the other hand, $S$. oryzae is practically restricted to warehousing, remaining constantly exposed to a selection pressure by insecticides [32], which favors the evolution of resistance. Similar results were obtained by Samson and Parker [33] who reported better control of S. zeamais than S. oryzae when organophosphate insecticides were used, but the toxicity of pyrethroid deltamethrin was similar for both species. In Brazil, resistance to organophosphate insecticides was detected in several populations of S. oryzae [7]; but just slightly resistance to one insecticide of this group (chlorpyriphos methyl) was 

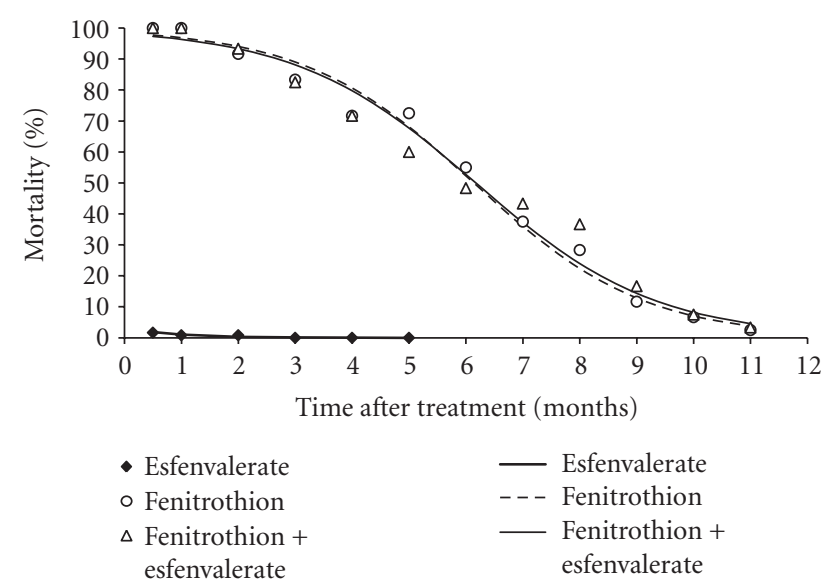

(a)

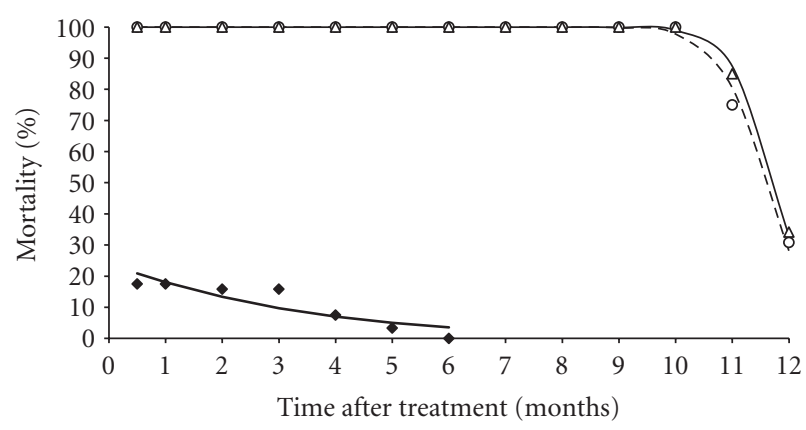

- Esfenvalerate

- Fenitrothion

$\Delta$ Fenitrothion + esfenvalerate

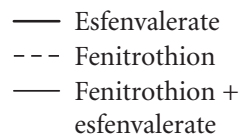

(b)

Figure 2: Mortality observed and adjusted curves (stat.) using the linear logistic model as to time after treatment of maize grains, comparing the insecticides used to control S. oryzae (a) and $S$. zeamais (b).

detected in S. zeamais $[8,34]$. The higher susceptibility of $S$. zeamais compared to $S$. oryzae occurs because the first species presents greater flight activity, among other factors, favoring cross-infestation and gene flow, thus preserving the genes of susceptibility to insecticides [35].

No potentiation effect was observed for the mixture of insecticides against $S$. oryzae and S. zeamais, and fenitrothion was the only responsible for mortality in both species, as well as highly susceptible to this insecticide, except for $S$. oryzae in maize which time-by was controlled with difficulty (Figure 2(a)). Different results were reported by Daglish et al. [36] rating $0 \%$ S. oryzae mortality in rice grains treated with fenitrothion or deltamethrin, although the mixture of both was effective to control this pest, thus demonstrating the potentiation effect in-between these insecticides. Differences are due to two factors: first, the authors used a line age exposed to a constant selection pressure through fenitrothion, thus, resistant to the insecticide; and second, amid other factors, the toxic effect of the mixture depends on the chemical molecules involved. Although deltamethrin

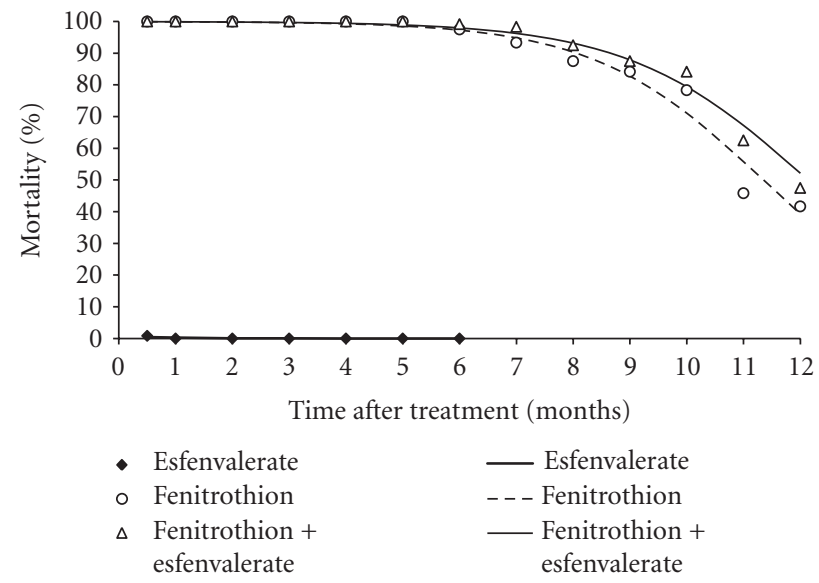

(a)

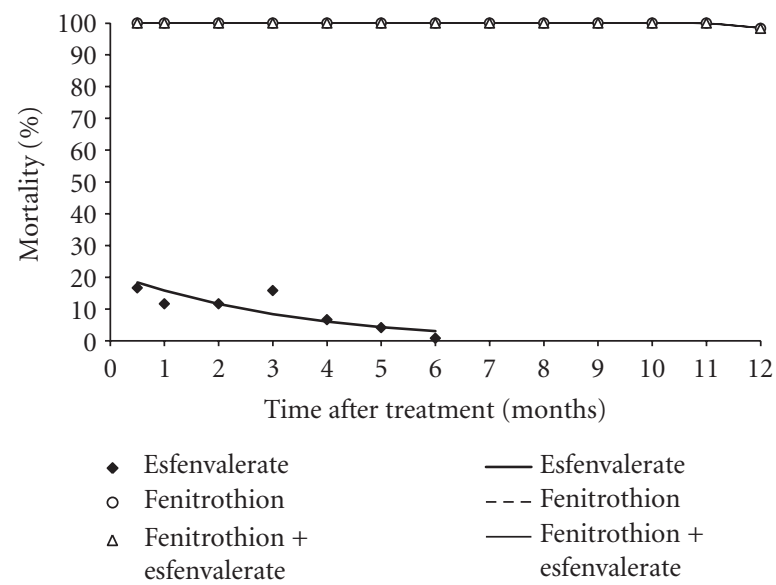

(b)

FIGURE 3: Mortality observed and adjusted curves (stat.) using the linear logistic model as to time after treatment of wheat grains, by comparing insecticides used to control S. oryzae (a) and S. zeamais (b).

and esfenvalerate are of the same chemical group, their interaction with fenitrothion in the control of the same pest species is different.

The higher mortality of both species in wheat grains treated with fenitrothion might be because such wheat has been into greater amount of insecticide than maize has, during grain treatment or because fenitrothion's degradation happens faster in maize than in wheat. To verify this, analyses of residues were carried out, concluding that deposits and degradation rates were similar in both types of grain. Consequently, the two hypotheses turn invalid.

The greater susceptibility to fenitrothion when both species were reared on wheat grains would be another hypothesis to explain for these results. Vásquez-Castro et al. [35], using the dry film method observed higher susceptibility of both species to fenitrothion when reared on wheat grains, compared to maize. On the other hand, due to the operational characteristics of the treatment, in which the grains were uniformly spread in a thin layer and treated 
by using a double-jet hydraulic nozzle (60 degree-betweenjets angle), and as to the morphological characteristics of grains, wheat presented a higher specific surface of contact to the drops. Therefore, the distribution of the insecticide on grain surface was much more uniform in wheat than in maize. Besides, both Sitophilus species are characterized by a great movement ability in grain mass, thus the movement of pests through the small spaces between grains favored the exposition to fenitrothion.

Conversely, Thaung and Collins [37] reported higher mortality of $S$. oryzae in maize grains compared to wheat. The method of application would be grounds for such contradicting results as these authors treated a small amount of grains within glass vials, which were then scrambled to distribute the insecticide as uniformly as possible. In the present experiment, grains were not revolved after treatments so that avoidance invalidates the studies as to applicationtechniques, responsible for the uniform distribution of insecticides $[19,38,39]$.

Rowlands [40], upon considering wheat grains as sample size to be analyzed, observed residue levels between zero and $252 \mathrm{mg} \cdot \mathrm{kg}^{-1}, 14$ weeks after applying malathion $\left(10 \mathrm{mg} \cdot \mathrm{kg}^{-1}\right)$. Thus, the nonuniformity of insecticide distribution can cause efficiency-loss on these products in protecting stored grains over time, besides the occurrence of samples containing residues above the maximum allowed by law, that is, endangering consumer's health and producer's economy.

3.2. F1 Progeny of S. oryzae and S. zeamais. Considering as random-components the Poisson distribution, and all the explanatory variables and interactions; the initial analysis presented very high residual deviance (14125) and $X^{2}$ (13501) compared to the 742 residual degrees of freedom, indicating overdispersion of data. Hence, the negative binomial distribution was considered as a random component of the model, that is, one of the ways to analyze overdispersed tallied data. The adjustment of the negative binomial model presented residual deviance (739.5) and $X^{2}$ (663.4) closer to the 742 residual degrees of freedom.

As observed in Table 2, there is a significant effect $(P<$ 0.05) of all the assessed causes of variation, except for the main effect of pest species and for the interactions month after treatment $x$ type of grain and month after treatment $x$ species $x$ insecticide $x$ type of grain. This result shows that the number of individuals of the F1 progeny depend on the four explanatory variables since all four triple interactions were significant. Thus, the unfolding of analysis was performed, evaluating the response curves as a function of time after treatment and the three other factors.

Table 3 presents the estimates of $\alpha$ and $\beta$ parameters from the negative binomial model for the combination of insecticide with pest species and type of grain. The estimated value of the number of insects of the F1 progeny was determined by $e^{\alpha+\beta x}$, for each combination of insecticide and pest species. Time after treatment is indicated by an $x$ in the expression and $e(=2.7183)$ is the natural number.

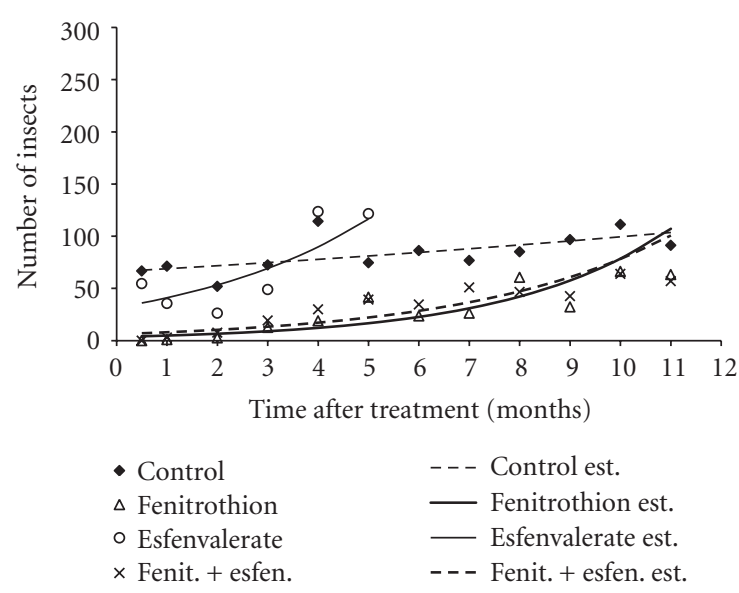

(a)

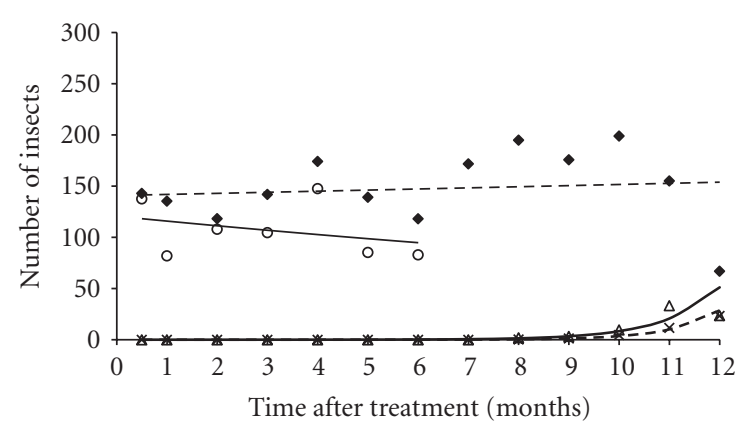

- Control

$\triangle$ Fenitrothion

- Esfenvalerate

$\times$ Fenit. + esfen.

- - - Control est.

- Fenitrothion est.

- Esfenvalerate est.

- - - Fenit. + esfen. est.

(b)

FIGURE 4: Average number of insects (F1) observed and curves adjusted by the negative binomial linear model as to time after treatment of maize grains, by comparing insecticides used to control $S$. oryzae (a) and S. zeamais (b).

One can notice that no significant effect $(P>0.05)$ of linear regression occurred only for the insecticide esfenvalerate applied to wheat grain to control S. oryzae and applied to maize grains to control S. zeamais, as well as for the control treatment concerning S. zeamais and in both types of grain. These results indicate that effect of time after insecticide application occurred on a number of insects of the $\mathrm{F} 1$ progeny in 12 out of the 16 combinations of insecticide with pest species and type of grain.

Figures 4-7 show tallies observed and the adjusted curves of the insects of F1 progeny, respectively, for each pest species and type of grain and for each insecticide.

Comparison of the four curves (three insecticides and one control) for each combination of pest and insecticide showed significant differences $(P<0.0001)$ in all cases, indicating that remarkable differences occur between at least two curves of two insecticides within the combination of pest species and type of grain (Figures 4 and 5). Except for some times after insecticide application, the control treatment presented estimated values of number of insects 
TABLE 2: Analysis of deviance for the negative binomial model, with logarithmic ligation function.

\begin{tabular}{|c|c|c|c|}
\hline Cause of variation & Degrees of freedom & Deviance & $\operatorname{Pr}>\chi^{2}$ \\
\hline Species & 1 & 3.79 & 0.0517 \\
\hline Insecticide & 3 & 284.19 & $<0.0001$ \\
\hline Type of grain & 1 & 18.97 & $<0.0001$ \\
\hline Month after treatment (MAT) & 1 & 109.7 & $<0.0001$ \\
\hline Species $\times$ Insecticide & 3 & 406.93 & $<0.0001$ \\
\hline Species $\times$ Type of grain & 1 & 77.40 & $<0.0001$ \\
\hline Insecticide $\times$ Type of grain & 3 & 38.26 & $<0.0001$ \\
\hline MAT $\times$ Species & 1 & 6.54 & 0.0105 \\
\hline MAT $\times$ Insecticide & 3 & 634.31 & $<0.0001$ \\
\hline MAT $\times$ Type of grain & 1 & 1.13 & 0.2868 \\
\hline Species $\times$ Insecticide $\times$ Type of grain & 3 & 20.70 & 0.0001 \\
\hline MAT $\times$ Species $\times$ Insecticide & 3 & 93.72 & $<0.0001$ \\
\hline MAT $\times$ Species $\times$ Type of grain & 1 & 7.12 & 0.0076 \\
\hline MAT $\times$ Insecticide $\times$ Type of grain & 3 & 102.81 & $<0.0001$ \\
\hline MAT $\times$ Species $\times$ Insecticide $\times$ Type of grain & 3 & 4.98 & 0.1731 \\
\hline
\end{tabular}

TABLE 3: Estimates of the $\alpha$ and $\beta$ parameters of the linear binomial model and probability descriptive level for the effect of linear regression of time after treatment as to species, insecticide, and type of grain.

\begin{tabular}{|c|c|c|c|c|c|c|}
\hline \multirow{2}{*}{ Insecticide } & \multicolumn{3}{|c|}{ S. oryzae } & \multicolumn{3}{|c|}{ S. zeamais } \\
\hline & $\alpha$ & $\beta$ & Linear regression $\left(\operatorname{Pr}>\chi^{2}\right)$ & $\alpha$ & $\beta$ & Linear regression $\left(\operatorname{Pr}>\chi^{2}\right)$ \\
\hline & \multicolumn{3}{|c|}{ Maize } & \multicolumn{3}{|c|}{ Maize } \\
\hline Control & 4.1928 & 0.0406 & 0.0072 & 4.9472 & 0.0075 & 0.5805 \\
\hline Esfenvalerate & 3.4543 & 0.2609 & $<0.0001$ & 4.7926 & -0.0402 & 0.4677 \\
\hline Fenitrothion & 1.2569 & 0.3107 & $<0.0001$ & -6.8929 & 0.9024 & $<0.0001$ \\
\hline \multirow[t]{2}{*}{ Fenit. + Esfen. } & 1.8438 & 0.2516 & $<0.0001$ & -9.0775 & 1.0361 & $<0.0001$ \\
\hline & \multicolumn{3}{|c|}{ Wheat } & \multicolumn{3}{|c|}{ Wheat } \\
\hline Control & 5.1084 & 0.0418 & 0.0012 & 4.9719 & 0.0165 & 0.1787 \\
\hline Esfenvalerate & 5.2773 & -0.0920 & 0.0534 & 5.2261 & -0.2507 & $<0.0001$ \\
\hline Fenitrothion & -0.4039 & 0.6145 & $<0.0001$ & -21.0609 & 1.9574 & $<0.0001$ \\
\hline Fenit. + Esfen. & -0.4534 & 0.5886 & $<0.0001$ & -14.2542 & 1.2609 & 0.0051 \\
\hline
\end{tabular}

of F1 progeny always superior than other treatments, for both pests and types of grain. The insecticide esfenvalerate presented intermediate values in the control of pest progeny, fenitrothion, and fenitrothion + esfenvalerate showed the best results in controlling the progeny and curves of the two insecticides were not significantly different in the control of $S$. oryzae progeny in both types of grain (Figures 4(a) and $5(\mathrm{a}))$. In the other cases, significant differences always occurred $(P<0.05)$ between curves.

As expected, the control treatments of both species presented the number of progeny higher than insecticide treatments along the experiment; although, now and then the opposite occurred, as observed in S. oryzae on maize grains treated with esfenvalerate in the fifth month after treatment (Figure $4(\mathrm{a}))$, S. oryzae on wheat grains treated with esfenvalerate at 15 days after treatment and at 12 months when grains were treated with fenitrothion (Figure 5(a)). In the effectiveness experiments, 40 unsexed insects were placed in each plot and so unknown is the number of females and males utilized in tests. It is possible that the number of females was higher in treatments and early mentioned dates, affecting the results of progeny. But considering the sex ratio of both species as $1: 1$ [3] and that randomly was insect capture, the probability of males and females utilized for effectiveness tests is the same. In this regard, works are found in international literature being this factor disregarded in progeny evaluation, as only standardizing parental age [14-16], as this report has hypothesized.

On the other hand, there is a biological phenomenon known as "hormoligosis" in which sublethal amounts of the insecticide can stimulate pest population growth [41]. This phenomenon has been reported by numerous researchers in several fields of biology and the hypothesis of its occurrence has being reinforced over the past 50 years [42]. Results showed that the $S$. oryzae progeny exposed to a certain insecticide and type of grain was higher than to control only in one date of evaluation which suggests that only one concentration of insecticide has a stimulant effect on the reproduction of the species. Morse and Zareh [43] observed that the acaricide Dicofol and the insecticides esfenvalerate, formetanate, and malathion significantly increased female fecundity when applied at doses that killed between 0.01 


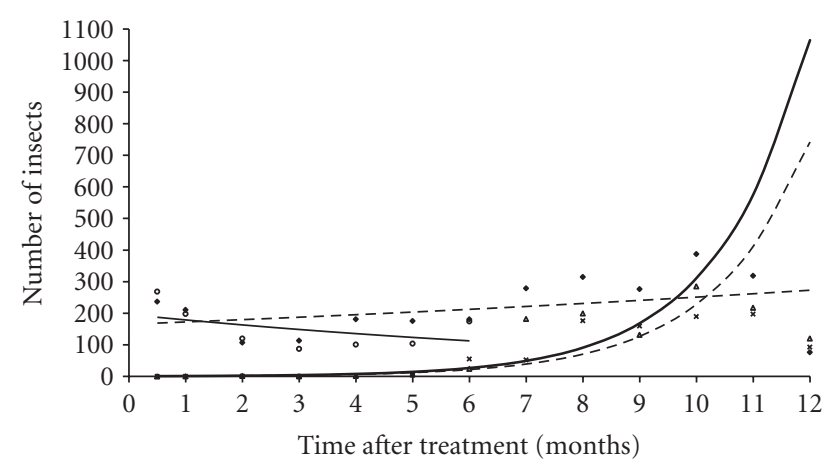

- Control

- Fenitrothion

- Esfenvalerate

* Fenit. + esfen.

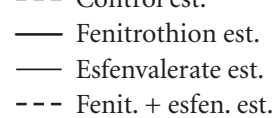

(a)

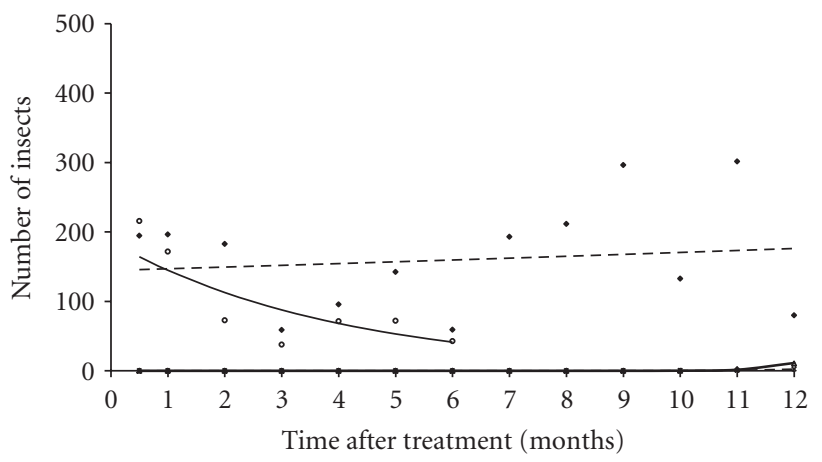

- Control

- Fenitrothion

- Esfenvalerate

* Fenit. + esfen.

- - - Control est.

- Fenitrothion est.

- Esfenvalerate est.

- - - Fenit. + esfen. est.

(b)

FIGURE 5: Average number of insects (F1) observed and curves adjusted by the negative binomial linear model as to time after treatment of wheat grains, by comparing insecticides used to control S. oryzae (a) and S. zeamais (b).

and $1 \%$ of the population of Scirtothrips citri (Moulton). Thus, the increase of progeny appears to be dependent on insecticide concentration. Besides this species, hormoligosis has also been reported in coleopteran-pest of stored grains, including S. granarius (L.) [44] and S. zeamais [45]. However, hormoligosis is a complex phenomenon involving many variables, including different insecticides for the same species, different species for the same insecticide and different conditions of tests for the same combination species insecticide. Thus, the simple demonstration of this phenomenon in individual growth, survival, or reproductive ability is insufficient to determine the ecological risk [46].

Evaluating control treatment, one can notice that $S$. oryzae presented greater progeny in wheat than in maize (Figure 6). Similar results were reported by Thaung and Collins [37] and Coombs and Porter [47]. Apparently, maize is a low-quality food for $S$. oryzae, causing less offspring compared to that of wheat. On the other hand, S. zeamais

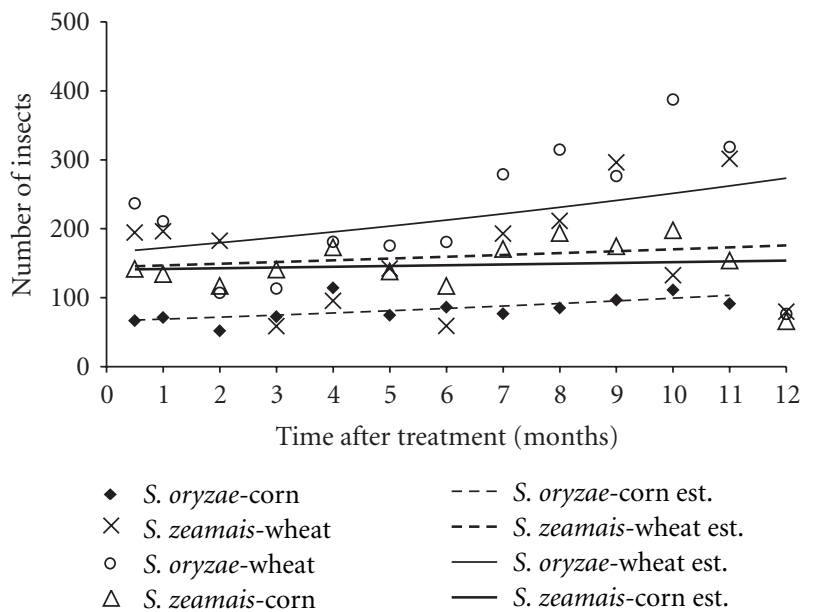

FIGURE 6: Average number of insects (F1) observed and curves adjusted by the negative binomial linear model as to time after control treatment, by comparing pest species and type of grain.

presented similar adjusted curves $(P=0.4759)$ in both types of grain. In general, the greatest progeny number was observed in S. oryzae reared on wheat grains, indicating the great importance of this pest in this type of grain.

As for other insecticides, the adjusted curves were always significantly different $(P<0.05)$ concerning pests and types of grain. The curve of $S$. oryzae infesting wheat presented higher values in most of the insecticide evaluations (Figure 7). Although fenitrothion and the fenitrothion + esfenvalerate mixture have caused higher S. oryzae mortality in wheat than in maize, higher progeny number was observed on wheat grains. An explanation for these results is that parents were able to lay eggs before being killed by insecticides. Both Sitophilus species are characterized by oviposit inside the grains [3], and after hatching the larvae feed on the starchy endosperm, a region of the grain rich in carbohydrates needed for larval growth. Nevertheless, if grain does not present appropriate food support the larvae tend to feed on germen in order to complete its cycle [48]. On the other hand, chemical insecticides are characterized by displacing mainly to the germ, region of the grain rich in oil, and in smaller amounts to the starchy endosperm [49]. So, the immature stages of these species will be exposed to low amounts of insecticides, allowing survival to those more tolerant species, as observed in S. oryzae. Differently, if the larva needs to feed on germen aiming at completing its cycle; will be killed, and damage will have already happened.

This study demonstrates the great efficiency of fenitrothion in controlling S. oryzae and S. zeamais. However, it should be wisely used, in programs of insecticide rotation and other control strategies. On the other hand, the type of grain affects the efficiency of the insecticide, thus, the dose should not be the same to maize and wheat and studies are necessary by targeting to determine the correct dose for each of these grains. 


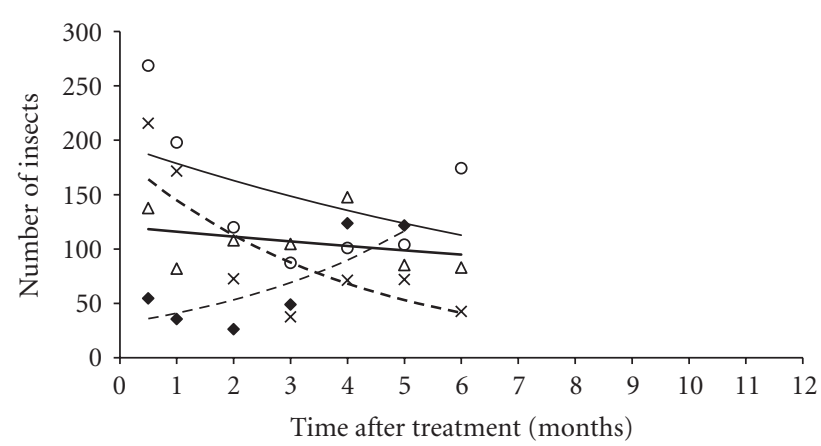

- S. oryzae-corn $\times$ S. zeamais-wheat - S. oryzae-wheat $\triangle$ S. zeamais-corn

$$
\begin{aligned}
& --- \text { S. oryzae-corn est. } \\
& --- \text { S. zeamais-wheat est. } \\
& - \text { S. oryzae-wheat est. } \\
& - \text { S. zeamais-corn est. }
\end{aligned}
$$

(a)

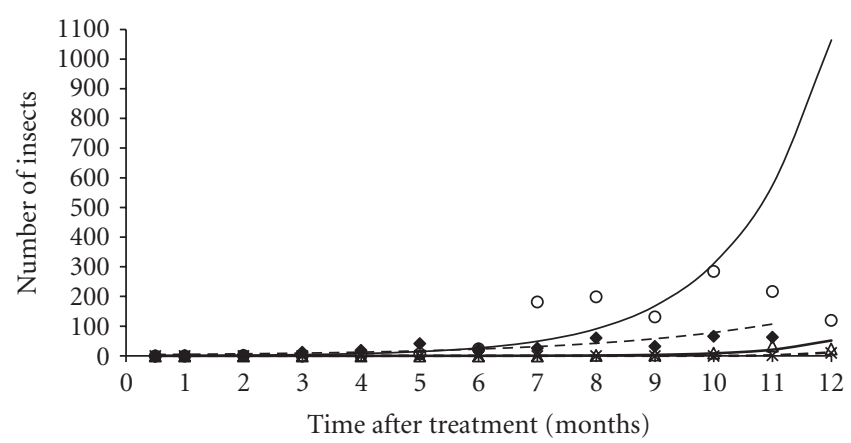

- S. oryzae-corn $\times$ S. zeamais-wheat - S. oryzae-wheat $\triangle$ S. zeamais-corn
- - S. oryzae-corn est. - - - S. zeamais-wheat est. - S. oryzae-wheat est. - S. zeamais-corn est.

(b)

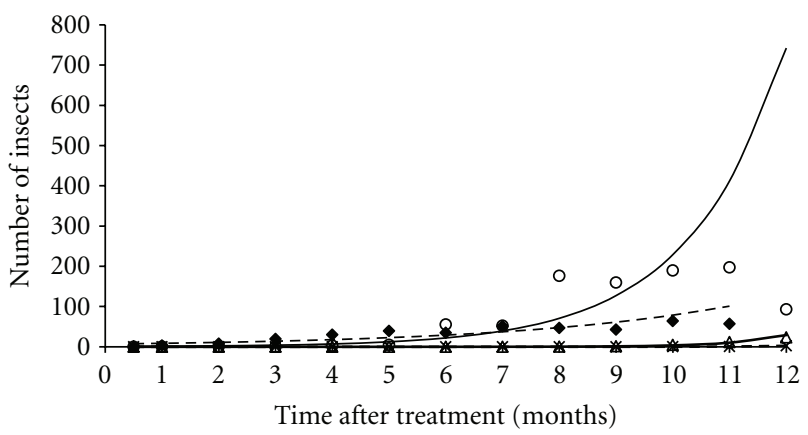

- S. oryzae-corn

- - S. oryzae-corn est.

$\times$ S. zeamais-wheat

- - - S. zeamais-wheat est.

- S. oryzae-wheat

- S. oryzae-wheat est.

$\triangle$ S. zeamais-corn

- S. zeamais-corn est.

(c)

FIGURE 7: Average number of insects (F1) observed and curves adjusted by the negative binomial linear model as to time after treatment with esfenvalerate (a), fenitrothion (b), and fenitrothion + esfevalerate mixture (c), by comparing pest species and type of grain.

\section{Disclaimer}

This report represents the results of the research only. Mentioning a proprietary product or trade name does not constitute a recommendation, or an endorsement issued by Universidad Nacional Agraria La Molina or by Escola Superior de Agricultura Luiz de Queiroz, Universidade de São Paulo.

\section{Acknowledgments}

The authors thank Carlos E. Longatti and Juliana Sabadin for their logistic support, Valter Arthur and Marcio Tavares for supplying insects necessary to start rearing $S$. oryzae and $S$. zeamais in laboratory, and Arlei Coldebella for his statistical analysis orientation.

\section{References}

[1] P. Beskow and D. Deckers, "Legislação brasileira de armazenamento de grãos," in Armazenagem de Grãos, I. Lorini, L. H. Miike, and V. M. Scussel, Eds., pp. 27-53, Instituto Bio Geneziz, Campinas, Brazil, 2002.
[2] D. Gallo, O. Nakano, S. Silveira Neto et al., Entomologia Agrícola, FEALQ, Piracicaba, Brazil, 2002.

[3] I. Athié and D. C. Paula, Insetos de Grãos ArmazenadosAspectos Biológicos e Identificação, Varela, São Paulo, Brazil, 2nd edition, 2002.

[4] P. S. Hindmarsh and I. A. MacDonald, "Field trials to control insect pests of farm-stored maize in Zambia," Journal of Stored Products Research, vol. 16, no. 1, pp. 9-18, 1980.

[5] P. J. Collins, T. M. Lambkin, B. W. Bridgeman, and C. Pulvirenti, "Resistance to grain-protectant insecticides in coleopterus pests of stored cereals in Queensland, Australia," Journal of Economic Entomology, vol. 86, pp. 239-245, 1993.

[6] E. Sgarbiero, L. R. P. Trevizan, and G. C. de Baptista, "Pirimiphos-methyl residues in corn and popcorn grains and some of their processed products and the insecticide action on the control of Sitophilus zeamais mots. (Coleoptera: Curculionidae)," Neotropical Entomology, vol. 32, no. 4, pp. 707-711, 2003.

[7] I. A. Pacheco, M. R. Sartori, and S. Bolonhezi, "Resistência ao malation, pirimifós-metílico e ao fenitrotion em coleopterospraga de grãos armazenados-fase II," Revista Brasileira de Armazenamento, vol. 18, pp. 32-39, 1993.

[8] B. M. Ribeiro, R. N. C. Guedes, E. E. Oliveira, and J. P. Santos, "Insecticide resistance and synergism in Brazilian populations 
of Sitophilus zeamais (Coleoptera: Curculionidae)," Journal of Stored Products Research, vol. 39, no. 1, pp. 21-31, 2002.

[9] F. H. Arthur, "Grain protectants: current status and prospects for the future," Journal of Stored Products Research, vol. 32, no. 4, pp. 293-302, 1996.

[10] C. G. Athanassiou, N. G. Kavallieratos, F. C. Tsaganou, B. J. Vayias, C. B. Dimizas, and C. T. Buchelos, "Effect of grain type on the insecticidal efficacy of SilicoSec against Sitophilus oryzae (L.) (Coleoptera: Curculionidae)," Crop Protection, vol. 22, no. 10, pp. 1141-1147, 2003.

[11] F. H. Arthur, B. Yue, and G. E. Wilde, "Susceptibility of stored-product beetles on wheat and maize treated with thiamethoxam: effects of concentration, exposure interval, and temperature," Journal of Stored Products Research, vol. 40, no. 5, pp. 527-546, 2004.

[12] N. G. Kavallieratos, C. G. Athanassiou, F. G. Pashalidou, N. S. Andris, and Z. Tomanović, "Influence of grain type on the insecticidal efficacy of two diatomaceous earth formulations against Rhyzopertha dominica (F) (Coleoptera: Bostrychidae)," Pest Management Science, vol. 61, no. 7, pp. 660-666, 2005.

[13] J. D. Stark and J. E. Banks, "Population-level effects of pesticides and other toxicants on arthropods," Annual Review of Entomology, vol. 48, pp. 505-519, 2003.

[14] F. H. Arthur, "Knockdown, mortality, and progeny production of lesser grain borers (Coleoptera: Bostrichidae) and rice weevils (Coleoptera: Curculionidae) exposed for short intervals on wheat treated with cyfluthrin," Journal of Economic Entomology, vol. 92, no. 5, pp. 1198-1205, 1999.

[15] G. J. Daglish and B. E. Wallbank, "Efficacy of diflubenzuron plus methoprene against Sitophilus oryzae and Rhyzopertha dominica in stored sorghum," Journal of Stored Products Research, vol. 41, no. 3, pp. 353-360, 2005.

[16] C. G. Athanassiou, "Toxicity of beta cyfluthrin applied alone or in combination with diatomaceous earth against adults of Sitophilus oryzae (L.) (Coleoptera: Curculionidae) and Tribolium confusum DuVal (Coleoptera: Tenebrionidae) on stored wheat," Crop Protection, vol. 25, no. 8, pp. 788-794, 2006.

[17] Agência Nacional de Vigilância Sanitária, "Monografías de agrotóxicos," 2010, http://portal.anvisa.gov.br/wps/portal/ anvisa/home.

[18] T. L. Adelsbach and R. S. Tjeerdema, "Chemistry and fate of fenvalerate and esfenvalerate," Reviews of Environmental Contamination and Toxicology, vol. 176, pp. 137-154, 2003.

[19] J. A. Vásquez-Castro, G. C. De Baptista, C. D. Gadanha Jr., and L. R. P. Trevizan, "A system to evaluate the performance of hydraulic nozzles used in stored grain protection trials," Scientia Agricola, vol. 64, no. 6, pp. 563-568, 2007.

[20] J. A. Vásquez-Castro, G. C. De Baptista, C. D. Gadanha Jr., and L. R. P. Trevizan, "Effect of spray volume on the moisture of stored corn and wheat grains," Brazilian Archives of Biology and Technology, vol. 51, no. 3, pp. 453-456, 2008.

[21] SAS Institute, SAS/STAT User's Manual, SAS Institute, Cary, NC, USA, 8th edition, 1999.

[22] C. G. B. Demétrio, Modelos Lineares Generalizados em Experimentação Agronômica, ESALQ, Piracicaba, Brazil, 3th edition, 2002.

[23] A. J. Prickett, "The cross-resistance spectrum of Sitophilus granarius (L.) (Coleoptera: Curculionidae) heterozygous for pyrethrin resistance," Journal of Stored Products Research, vol. 16, no. 1, pp. 19-25, 1980.

[24] N. W. Heather, "Sex-linked resistance to pyrethroids in Sitophilus oryzae (L.) (Coleoptera: Curculionidae)," Journal of Stored Products Research, vol. 22, no. 1, pp. 15-20, 1986.
[25] R. N. C. Guedes, Detecção e herança da resistência ao DDT e a piretróides em Sitophilus zeamais Motschulsky (Coleoptera: Curculionidae) [M.S. thesis], Universidade Federal de Viçosa, Viçosa, Brazil, 1993.

[26] P. R. Samson, R. J. Parker, and E. A. Hall, "Synergized deltamethrin as a protectant against Sitophilus zeamais Motsch. and S. oryzae (L.) (Coleoptera: Curculionidae) on stored maize," Journal of Stored Products Research, vol. 26, no. 3, pp. 155-161, 1990.

[27] I. Lorini and D. J. Galley, "Effect of the synergists piperonyl butoxide and DEF in deltamethrin resistance on strains of Rhyzopertha dominica (F.) (Coleoptera: Bostrychidae)," Anais da Sociedade Entomológica do Brasil, vol. 29, pp. 749-755, 2000.

[28] E. A. Bitran, T. B. Campos, D. A. Oliveira, and S. Chiba, "Avaliação da ação residual de alguns inseticidas organofosforados e piretróides no controle de infestações de Sitophilus zeamais Motschulsky, 1855, em milho armazenado," Biológico, vol. 49, pp. 265-273, 1983.

[29] M. Bengston, R. A. H. Davies, J. M. Desmarchelier et al., "Organophosphorothioates and synergised synthetic pyrethroids as grain protectants on bulk wheat," Pesticide Science, vol. 14, pp. 373-384, 1983.

[30] P. H. Giles and F. Ashman, "A study of pre-harvest infestation of maize by Sitophilus zeamais Motsch. (Coleoptera, Curculionidae) in the Kenya highlands," Journal of Stored Products Research, vol. 7, no. 2, pp. 69-83, 1971.

[31] T. L. Chesnut, "Flight habits of the maize weevil as related to field infestation of corn," Journal of Economic Entomology, vol. 65, pp. 434-435, 1972.

[32] B. R. Champ and J. N. Cribb, "Lindane resistance in Sitophilus oryzae (L.) and Sitophilus zeamais Motsch. (Coleoptera, Curculionidae) in Queensland," Journal of Stored Products Research, vol. 1, no. 1, pp. 9-24, 1965.

[33] P. R. Samson and R. J. Parker, "Laboratory studies on protectants for control of Coleoptera in maize," Journal of Stored Products Research, vol. 25, no. 1, pp. 49-55, 1989.

[34] D. B. Fragoso, R. N. C. Guedes, and S. T. Rezende, "Glutathione S-transferase detoxification as a potential pyrethroid resistance mechanism in the maize weevil, Sitophilus zeamais," Entomologia Experimentalis et Applicata, vol. 109, no. 1, pp. 21-29, 2003.

[35] J. A. Vásquez-Castro, G. C. de Baptista, L. R. P. Trevizan, and C. D. Gadanha, "Flight activity of Sitophilus oryzae (L) and Sitophilus zeamais Motsch (Coleoptera: Curculionidae) and its relationship with susceptibility to insecticides," Neotropical Entomology, vol. 38, no. 3, pp. 405-409, 2009.

[36] G. J. Daglish, M. Eelkema, and L. M. Harrison, "Control of Sitophilus oryzae (L.) (Coleoptera: Curculionidae) in paddy rice using chlorpyrifos-methyl or fenitrothion in combination with several other protectants," Journal of Stored Products Research, vol. 32, no. 3, pp. 247-253, 1996.

[37] M. Thaung and P. J. Collins, "Joint effects of temperature and insecticides on mortality and fecundity of Sitophilus oryzae (Coleoptera: Curculionidae) in wheat and maize," Journal of Economic Entomology, vol. 79, pp. 909-914, 1986.

[38] J. A. Vásquez-Castro, G. C. De Baptista, C. D. Gadanha Jr., and L. R. P. Trevizan, "Influence of emulsifiable concentrate formulation on the physical properties of the fluid, spray characteristics, and insecticide deposits on stored grains," Journal of Agricultural and Food Chemistry, vol. 55, no. 9, pp. 3529-3534, 2007.

[39] J. A. Vásquez-Castro, G. C. De Baptista, C. D. Gadanha Jr., and L. R. P. Trevizan, "Effectiveness of the standard 
evaluation method for hydraulic nozzles employed in stored grain protection trials," Revista Colombiana de Entomologia, vol. 34, no. 2, pp. 182-187, 2008.

[40] D. G. Rowlands, "The metabolism of contact insecticides in stored grains. II. 1966-1969,” Residue Reviews, vol. 34, pp. 91$161,1971$.

[41] J. G. Morse, "Agricultural implications of pesticide-induced hormesis of insects and mites," Human and Experimental Toxicology, vol. 17, no. 5, pp. 266-269, 1998.

[42] E. J. Calabrese and L. A. Baldwin, "The marginalization of hormesis," Human and Experimental Toxicology, vol. 19, no. 1, pp. 32-40, 2000.

[43] J. G. Morse and N. Zareh, "Pesticide-induced hormoligosis of citrus thrips (Thysanoptera: Thripidae) fecundity," Journal of Economic Entomology, vol. 84, pp. 1169-1174, 1991.

[44] D. J. Kuenen, "Influence of sublethal doses of DDT upon the multiplication rate of Sitophilus granarius (Coleopt. Curculionidae)," Entomologia Experimentalis et Applicata, vol. 1, no. 2, pp. 147-152, 1958.

[45] N. M. P. Guedes, J. Tolledo, A. S. Corrêa, and R. N. C. Guedes, "Insecticide-induced hormesis in an insecticideresistant strain of the maize weevil, Sitophilus zeamais," Journal of Applied Entomology, vol. 134, no. 2, pp. 142-148, 2010.

[46] V. E. Forbes, "Is hormesis an evolutionary expectation?" Functional Ecology, vol. 14, no. 1, pp. 12-24, 2000.

[47] C. W. Coombs and J. E. Porter, "Some factors affecting the infestation of wheat and maize by Sitophilus oryzae (L.) and Sitophilus zeamais Mots. (Coleoptera: Curculionidae)," Journal of Stored Products Research, vol. 22, no. 1, pp. 33-41, 1986.

[48] C. H. Matioli, J. C. Matioli, and A. A. Almeida, "Localização dos orifícios de emergência dos adultos de Sitophilus oryzae (L., 1763) nos grãos de milho," Revista Brasileira de Armazenamento, vol. 13, pp. 22-24, 1988.

[49] D. G. Rowlands and J. S. Bramhall, "The uptake and translocation of malathion by the stored wheat grain," Journal of Stored Products Research, vol. 13, no. 1, pp. 13-22, 1977. 


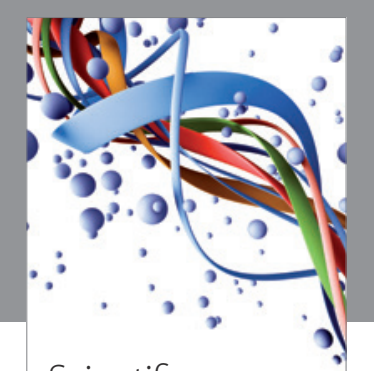

Scientifica
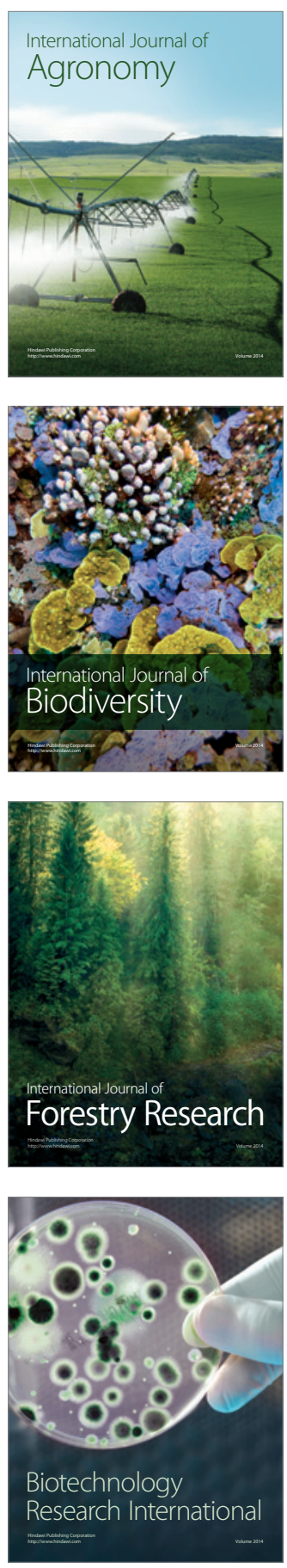
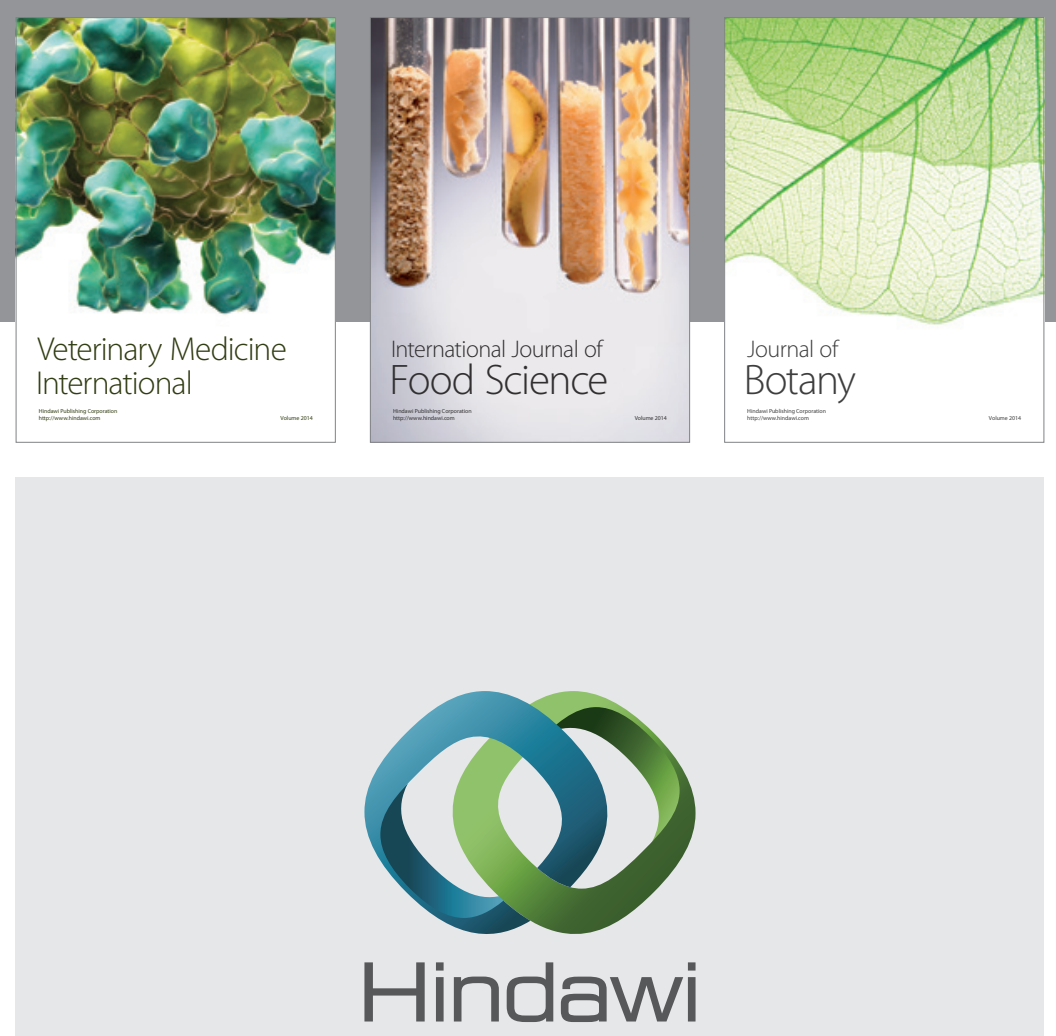

Submit your manuscripts at

http://www.hindawi.com
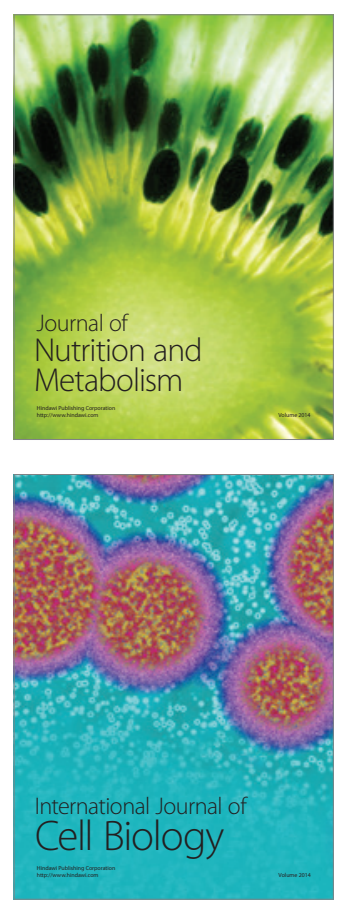
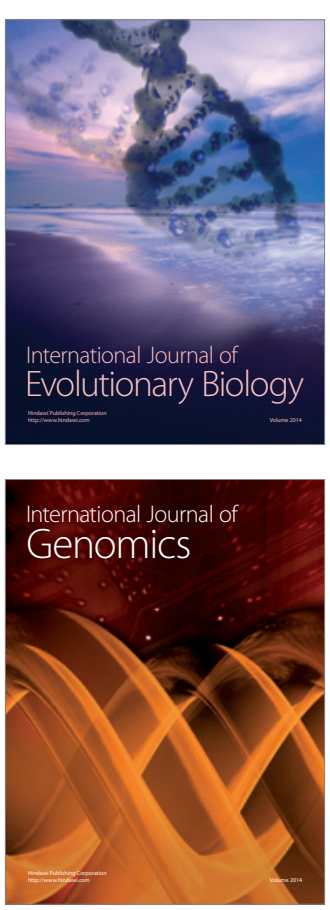
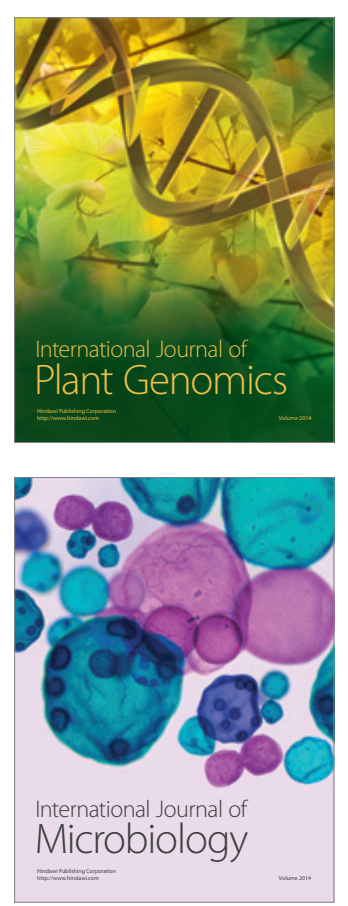

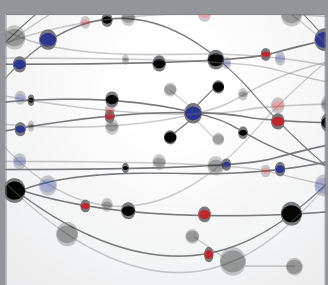

The Scientific World Journal
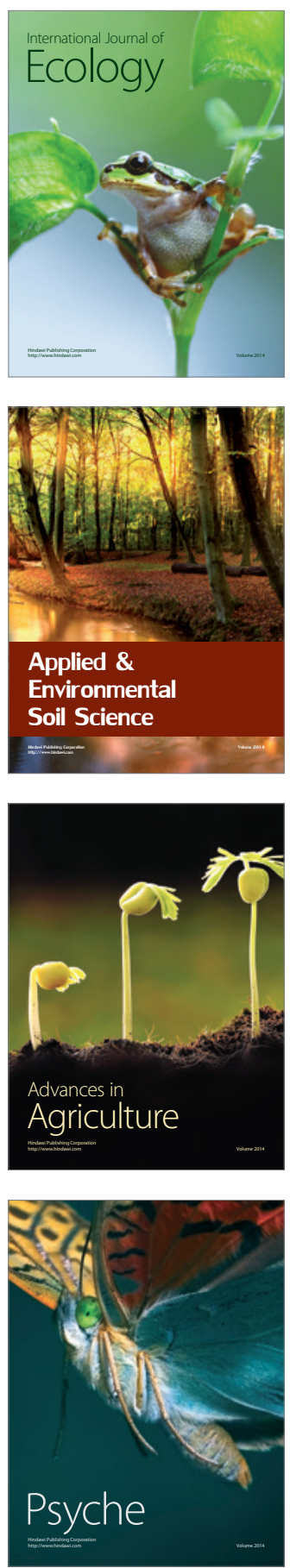